\title{
Editorial
}

\section{Resource Based Relative Value Scale for children-comparison of pediatric and cardiology work value}

\author{
Nicholas Hunt
}

$A$ NYONE WHO HAS WORKED IN THE FIELD OF CHILDREN'S medicine or the organization of its delivery would never doubt that the complexity of children's care compared to adult care is largely unrecognized and unrewarded. Indeed, as we increase our knowledge about ourselves and our health, or lack of it, it is increasingly clear that each stage of life carries with it a different set of health challenges and opportunities. This will need to be recognized more and more as we develop increasingly sophisticated research data, costing systems and health care coding. In the delivery of health services we have yet to return even to the Ancients' notion of the seven ages of man and what each stage might mean in terms of health, but it is now a generally held belief that there are very different health needs arising from age. At present, age is usually only recognized in terms of infancy, childhood, adolescence, adulthood and old age. Despite this, current procedural terminology codes generally do not distinguish between patients based on age or etiology of disease.

The study by Garson et al, ${ }^{1}$ jointly undertaken by the American College of Cardiology and the Cardiology Section of the American Academy of Pediatrics, was set up to compare relative work values for the most commonly used procedural terminology codes between adult and pediatric cardiology. The study achieves an admirable demonstration of two generally ignored facts. The first is that pediatrics is harder work, diagnosis for diagnosis. The second is that current coding systems do not adequately recognize the difference between adult and pediatric medicine. Not only does the study conclude that work values for cardiology are different between children and adults but, most strikingly, that this is the case in $75 \%$ of the services assessed. The magnitude of these differences should, as is acknowledged in the study, be confirmed in a broader study. It is to be hoped that further studies will look at other specialties and also begin to recognize the difference between the various age ranges as described above. There is no reason why, if we are to distinguish between children and adults, we cannot include a comparativelook at adolescents

Accepred for publication 31 January 1995 and the elderly.

Despite elaborate mechanisms for the achievement of objectivity, it is not unfeasible that the participants in this study unconsciously gave "higher" work values for pediatric medicine than adult medicine because of the additional emotive content in dealing with sick infants and young people. Certainly, through omission, the study raises one other important aspect of pediatric medical practice, which is that there is undoubtedly as much concentration on parents/ relatives/significant care-giver as on the patient. The Hsaio study, which was used to define physician work, includes mental effort, intensityand psychological stressinthedefinition. This is clearly sensible but, for the pediatrician, account must also be taken of the additional factors surrounding communication, consent and the number of people contributing to the debate over the care of any one patient.

For the United States of America, developing this work might well have important ramifications for rewarding physician time. In the United Kingdom, it will be important for recognizing that costing service by diagnosis alone will be insufficient in determining how much should be spent on pediatric services. The health world is better informed than ever before about the services, their outcomes and their costs. In the future, it will be crucial to develop coding and costing systems to reflect the difference in work values which the study explores.

Those involved in the delivery of children's health care can only be cheered by a study seeking to demonstrate that there is more to the definition of pediatric medicine than a diagnosis and procedure code. More please.

Director of Marketing and Contracts
Royal Brompton Hospital
Sydney Street
London SW3 6LY, United Kingdom
Fax. (O) 171 351-8473

\section{Reference}

1. Garson A Jr, Wolk MJ, Morrin SB, Gold W, Dickstein M, Dobson A. Resource Based Relative Value Scale for children-comparison of pediatric and adult cardiology work values. Cardiol Young 1995; 5: 210-216. 